\title{
Obesity and Breast Cancer Screening
}

\section{The Influence of Race, Illness Burden, and Other Factors}

Christina C. Wee, MD, MPH, Ellen P. McCarthy, PhD, MPH, Roger B. Davis, ScD, Russell S. Phillips, MD

BACKGROUND: Compared to normal weight women, women with obesity have higher mortality from breast cancer but are less often screened.

OBJECTIVES: To examine the relation between mammography use and weight category and to examine the influence of race, illness burden, and other factors on this relationship.

DESIGN AND SETTING: The 1998 National Health Interview Survey, a U.S. civilian population-based survey.

PARTICIPANTS: Five thousand, two hundred, and seventyseven women ages 50 to 75 years who responded to the Sample Adult and Prevention questionnaires.

MEASUREMENTS: Mammogram use in the preceding 2 years.

RESULTS: Among 5,277 eligible women, $72 \%$ reported mammography use. The rate was $74 \%$ among white women and 70\% among black women. Among white women, mammogram use was lowest in women with a body mass index (BMI) greater than $35 \mathrm{~kg} / \mathrm{m}^{2}$ (64\% to $67 \%$ ). After adjusting for sociodemographic factors, health care access, medical conditions, hospitalizations, and mobility status, higher BMI was associated with lower screening among white women, $P=.02$ for trend; the relative risk ( $R R$ ) for screening in moderately obese white women (BMI, 35 to $40 \mathrm{~kg} / \mathrm{m}^{2}$ ) was 0.83 (95\% confidence interval [CI], 0.68 to 0.96 ) compared to normal weight white women. Compared to normal weight black women, mammography use was similar or higher in overweight (BMI, 25 to $30 \mathrm{~kg} / \mathrm{m}^{2}$; RR, 1.19; $95 \%$ CI, 1.01 to 1.32), mildly obese (BMI, 30 to $35 \mathrm{~kg} / \mathrm{m}^{2}$; RR, 1.22; 95\% CI, 0.98 to 1.39), and moderately obese black women (RR, 1.37; 95\% CI, 1.37 to 1.50 ) after adjustment. The $P$ value for the race-BMI interaction was .001 . Results for white and black women were unchanged after additional adjustment for psychological functioning and health habits.

CONCLUSION: Among white women, those with higher BMI were less likely to undergo breast cancer screening than normal weight women. This relationship was not seen in black women. Our findings were not explained by differences in sociodemographic factors, health care access, illness burden, or health habits. More research is needed to determine the reasons for these disparities so that appropriate efforts can be made to improve screening.

KEY WORDS: breast cancer; cancer screening; ethnicity; obesity; race.

J GEN INTERN MED 2004;19:324-331.

Received from the Division of General Medicine and Primary Care (CCW, EPM, RBD, RSP), Beth Israel Deaconess Medical Center, Harvard Medical School, Boston, Mass.

Address correspondence and requests for reprints to Dr. Wee: Division of General Medicine and Primary Care, Beth Israel Deaconess Medical Center, Rose 115, Boston, MA 02215 (e-mail: cweekuo@bidmc.harvard.edu).
O besity is the second leading cause of preventable deaths, ${ }^{1,2}$ and a large proportion of these deaths is due to cancer. ${ }^{3}$ Women with obesity have higher mortality rates for breast cancer than do thinner women. Despite the association between breast cancer and obesity, women who are obese are less likely to report mammography use even though early detection through mammography screening can reduce breast cancer deaths by $20 \%$ to $39 \%{ }^{4}$

The reasons for disparities in cancer screening by weight are not well understood. In an earlier study, our group found mammography use to be lower among women who were obese even after adjusting for sociodemographic factors, health care access, and general health status. One potential reason for this disparity may be the higher illness burden associated with obesity, which was not adequately accounted for in our prior study. ${ }^{5}$ Psychosocial factors may also contribute to disparities in screening by weight. ${ }^{5}$ In addition to societal discrimination, patients with obesity may face physician bias, ${ }^{5-9}$ which may in turn lead to poor patient-physician relationships and communication, and lower rates of screening. Furthermore, patients' selfperception and body image may affect preferences for screening. Studies suggest that overweight women are much more likely to have poor self-perception than thinner women. ${ }^{10-12}$ However, the effect of weight on self-image appears to vary by race, with weight having a more negative impact among white women than among black women. ${ }^{10-12}$ Our prior study found that cervical cancer screening rates did not differ by weight among black women even though overweight and obese white women reported lower rates of cervical cancer screening than normal weight white women. ${ }^{5}$ Whether disparities in breast cancer screening by weight also differ according to race is less clear. ${ }^{5}$

In this context, we used data from the 1998 National Health Interview Survey (NHIS) to examine whether the association between obesity and lower mammography use persists, and to examine the role of race, illness burden, and other factors on this relationship. We hypothesized that obesity-related disparities are primarily seen in white but not black women. Furthermore, we believed that differences by weight are independent of factors such as illness burden, access to care, and health-seeking behavior.

\section{METHODS}

\section{The 1998 National Health Interview Survey}

The NHIS is a continuing, in-person household survey of the civilian, noninstitutionalized U.S. population, conducted by the National Center for Health Statistics. ${ }^{13}$ Its main objective is to provide accurate and current 
information on the amount, distribution, and effects of illness and disability in the United States and the services rendered because of such conditions. In 1998, 98,785 persons (including children) from 38,775 households were surveyed, reflecting a response rate of $90 \%$.

The Family Core questionnaire elicits sociodemographic information, basic indicators of health status, and utilization of health care services for each household member. One randomly selected adult from each household $(N=32,440)$ is then administered supplemental questionnaires: the Sample Adult Core questionnaire collected information about height and weight, health care and utilization, health habits such as alcohol use, tobacco use, and physical activity level, common medical conditions, and functional status; the Adult Prevention questionnaire included questions about cancer screening such as mammography use. The response to this supplement was $84 \%$; the combined response rate for the core and supplemental surveys was $73 \%$.

Sampling is based on a complex multistage design with oversampling of certain minority groups. When adjusted for the sampling design, results from the core survey and subsamples are generalizable to the noninstitutionalized, civilian U.S. population.

\section{Breast Cancer Screening}

Women above age 30 were asked when they last had a mammogram. We considered women between 50 and 75 years as eligible for breast cancer screening because mammography reduces breast cancer mortality for this group by $20 \%$ to $39 \% .{ }^{4}$ We classified those who underwent a mammogram within the preceding 2 years as having adequate screening based on the guidelines established by the U.S. Preventive Services Task Force. ${ }^{14}$

\section{Categories of Body Weight}

We determined our main variable of interest, weight category, by first calculating body mass index (BMI; respondent's self-reported weight in kilograms divided by the square of their height in meters). Respondents were then categorized into nationally defined weight categories (48): 1) underweight $\left(<18.5 \mathrm{~kg} / \mathrm{m}^{2}\right)$, 2) normal weight (18.5 to $<25.0 \mathrm{~kg} / \mathrm{m}^{2}$ ), 3) overweight ( 25.0 to $<30.0 \mathrm{~kg} / \mathrm{m}^{2}$ ), 4) mild obesity ( 30.0 to $35.0 \mathrm{~kg} / \mathrm{m}^{2}$ ), 5) moderate obesity (35.0 to $\left.<40.0 \mathrm{~kg} / \mathrm{m}^{2}\right)$, and 6$)$ extreme obesity $\left(\geq 40.0 \mathrm{~kg} / \mathrm{m}^{2}\right){ }^{15}$

\section{Other Factors of Interest}

Demographic Factors. We included age, marital status (married, widowed, divorced or separated, living with a partner, or never married), race and ethnicity (nonHispanic white, non-Hispanic black, Hispanic, Asian American, and other), educational level (less than high school, high school graduate, some college, 4-year college degree, or higher), and region of the country (northeast, midwest, south, and west).
Access to Health Care. Access to health care was defined by insurance status, number of visits to health providers, and having a usual source of health care. Health insurance type included Medicare, Medicaid, private, managed care insurance, private fee-for-service insurance, other type, and no insurance. We described respondents' usual source or provider of care as general practitioner, gynecologist, subspecialist, usual place of care but no provider, and no place of usual care. The last group included those who indicated the emergency department as their usual source of health care.

Illness Burden. We used several indicators of illness and disease burden to capture respondents' illness burden. These indicators included hospitalizations, medical conditions, and mobility status. Respondents were asked about medical conditions from a list reflecting conditions that in previous years were either highly prevalent or accounted for disproportionate use of health services. ${ }^{13}$ We classified these conditions into hypertension, heart disease, stroke, asthma, diabetes, cancer (excluding breast and nonmelanoma skin cancer), chronic joint pain, chronic back pain, and other (e.g., stomach ulcer, and kidney or liver failure). Mobility status was categorized as no impairment, minor, moderate, or severe impairment, as previously described. ${ }^{16}$

Psychological Functioning. Respondents were asked whether they felt worthless or felt sad or hopeless in the preceding 30 days (not at all, somewhat, or very). We used responses to these 2 items as general markers of selfesteem and depressed mood, respectively.

Health Habits. We used respondents' health habits as proxy for health-seeking behavior. Health habits included smoking behavior, physical activity level, and alcohol use. We categorized smoking into never smoked, former smoker, and current smoker. Activity level was classified as low, moderate, and high, as described previously. ${ }^{17}$ Alcohol use was classified as none in the past year, $<1$ day per week, 1 to 2 drinks per day on 1 to 7 days of the week, 3 to 5 drinks on 1 to 7 days of the week, and 5 or more drinks per day on at least 3 days a year.

\section{Data Analysis}

We used descriptive statistics and bivariable analyses to characterize our sample by race and BMI. We used multivariable logistic regression to examine the adjusted relationship between BMI and breast cancer screening with mammography within the preceding 2 years as the dependent variable and the BMI categories as the independent variable. Analyses were conducted first among all women age 50 to 75 years and then among white and black women separately, and then among white and black together, with normal weight white women as the reference group. We introduced an interaction term for BMI and race in our primary analyses excluding underweight women to examine 
whether racial differences in the relationship between BMI and mammography use were statistically significant. Because mammography use was not an uncommon event and odds ratios do not approximate relative risks in this instance, we converted odds ratios to relative risks using a method described by Zhang and Yu. ${ }^{18}$

We first created an unadjusted logistic regression model. We then developed a series of adjusted models to examine the influence of specific factors on the relationship between BMI and mammography use. We first adjusted for demographic factors, general health status (5-category rating scale), and access to health care (model 1). For our primary analysis, we examined the influence of illness burden on BMI and screening by additionally adjusting for self-reported medical conditions, hospitalizations, and mobility status (model 2). In a subsample excluding underweight women, we also conducted a test for trend to examine whether there was a statistically significant doseresponse relationship between BMI and mammography use. We then explored the impact of self-esteem and depressed mood by adding our indicators of psychological functioning to our model (model 3). Finally, we further adjusted for health habits as a proxy for health-seeking behavior (model 4).

All analyses were weighted accordingly to adjust for nonresponse and to reflect national estimates. Standard errors were adjusted for the complex sampling design using SUDAAN (ITS, Austin, Tx) statistical software.

\section{RESULTS}

\section{Sample Characteristics by Race and BMI}

Of the 5,738 women between ages 50 and 75 years, 5,277 (92\%) had complete data on BMI, race, and mammography use. Of these women, $72 \%$ reported mammography use in the preceding 2 years. The rate was $74 \%$ for white women and $70 \%$ for black women $(P=.08)$. The prevalence of obesity ( $\mathrm{BMI} \geq 30 \mathrm{~kg} / \mathrm{m}^{2}$ ) in this age group was $23 \%$ among white women and $38 \%$ among black women $(P<.001)$. We noted significant differences in marital status, education, and the insurance status of black and white women (Table 1). Furthermore, compared to white women, black women were less likely to see a health provider in the preceding year but were more likely to be hospitalized and to have certain medical conditions and physical limitations (Table 1).

In both black and white women, we found similar associations between obesity and many clinical and sociodemographic factors. In black and white women, obesity was significantly associated with higher age, and lower education and income; obesity was also associated with poorer health status, higher numbers of medical conditions, and greater mobility difficulties. However, there were some differences by race. The relationship between BMI and source of health care varied slightly by race. Compared to normal weight white women, obese white women were more likely to have a usual source of care (97\% vs 95\%) and to have a specialist as their usual provider (4\% vs 3\%). Conversely,
Table 1. Characteristics of Women in Study Sample Overall and by Race

\begin{tabular}{|c|c|c|c|}
\hline & $\begin{array}{c}\text { All } \\
\text { Women } \\
N=5,277\end{array}$ & $\begin{array}{c}\text { White } \\
\text { Women } \\
N=3,880\end{array}$ & $\begin{array}{c}\text { Black } \\
\text { Women } \\
N=718\end{array}$ \\
\hline \multicolumn{4}{|l|}{ Demographics } \\
\hline $\begin{array}{l}\text { Portion of weighted } \\
\text { sample, } \%\end{array}$ & 100 & 80 & 10 \\
\hline Mean age, $\mathrm{y} \pm \mathrm{SD}$ & $61 \pm 9$ & $61 \pm 9$ & $60 \pm 8$ \\
\hline Married, \%* & 62 & 66 & 35 \\
\hline \multicolumn{4}{|l|}{ Education* } \\
\hline Less than high school & 23 & 17 & 40 \\
\hline College graduate & 16 & 18 & 10 \\
\hline \multicolumn{4}{|l|}{ Healthcare Access } \\
\hline \multicolumn{4}{|l|}{ Insurance type* } \\
\hline Uninsured & 7 & 5 & 12 \\
\hline Managed care & 18 & 19 & 19 \\
\hline Fee-for-service & 17 & 18 & 14 \\
\hline \multicolumn{4}{|l|}{ Source of usual care, $\%$} \\
\hline None & 4 & 4 & 7 \\
\hline $\begin{array}{l}\text { General Internist/ } \\
\text { family practitioner }\end{array}$ & 77 & 78 & 78 \\
\hline Gynecologist & 7 & 7 & 5 \\
\hline \multicolumn{4}{|l|}{ Physician visits, $n^{*}$} \\
\hline$\geq 1$ last year, $\%$ & 90 & 91 & 87 \\
\hline \multicolumn{4}{|l|}{ Illness Burden } \\
\hline $\begin{array}{l}\geq 1 \text { hospitalization in } \\
\text { past year, \%* }\end{array}$ & 12 & 11 & 16 \\
\hline \multicolumn{4}{|l|}{ Comorbidities, \% } \\
\hline Hypertension* & 41 & 39 & 61 \\
\hline Heart disease & 18 & 19 & 19 \\
\hline Asthma & 11 & 11 & 12 \\
\hline Diabetes* & 11 & 9 & 20 \\
\hline Chronic joint pain & 34 & 34 & 33 \\
\hline Low back pain & 34 & 35 & 35 \\
\hline \multicolumn{4}{|l|}{ Mobility Status* } \\
\hline Major impairment & 12 & 12 & 20 \\
\hline $\begin{array}{l}\text { Felt worthless in past } \\
30 \text { days }\end{array}$ & 10 & 8 & 9 \\
\hline $\begin{array}{l}\text { Felt sad/hopeless in } \\
\text { past } 30 \text { days }\end{array}$ & 31 & 29 & 32 \\
\hline \multicolumn{4}{|l|}{ Health Habits } \\
\hline \multicolumn{4}{|l|}{ Physical activity level* } \\
\hline Low, \% & 47 & 44 & 64 \\
\hline \multicolumn{4}{|l|}{ Smoking status* } \\
\hline Current, \% & 20 & 20 & 23 \\
\hline \multicolumn{4}{|l|}{ Alcohol use* } \\
\hline None in the past year & 51 & 47 & 70 \\
\hline$<1$ day per week & 28 & 30 & 20 \\
\hline $\begin{array}{l}1 \text { to } 2 \text { drinks per day on } \\
1 \text { to } 7 \text { days of the week }\end{array}$ & 16 & 18 & 6 \\
\hline $\begin{array}{l}3 \text { to } 5 \text { drinks on } 1 \text { to } \\
7 \text { days of the week }\end{array}$ & 2 & 2 & 1 \\
\hline $\begin{array}{l}\geq 5 \text { drinks on } \geq 3 \\
\quad \text { occasions, } \%\end{array}$ & 2 & 2 & 2 \\
\hline
\end{tabular}

$* \mathrm{P}<.05$ for comparisons between black and white women.

obese black women were less likely than normal weight black women to have a usual source of care (92\% vs $96 \%)$ or to have a specialist as their usual provider ( $1 \%$ vs $4 \%$ ). Furthermore, while obese white women reported a significantly higher hospitalization rate than normal weight white women (15\% vs 10\%), obese black women reported a 
Table 2. Mammography Use (\%) Among Women Age 50 to 75 years by Weight Category Before Adjustment

\begin{tabular}{|c|c|c|c|c|c|c|}
\hline & $\begin{array}{l}\text { Normal } \\
\text { Weight }\end{array}$ & $\begin{array}{l}\text { Over- } \\
\text { weight }\end{array}$ & $\begin{array}{l}\text { Mildly } \\
\text { Obese }\end{array}$ & $\begin{array}{c}\text { Moderately } \\
\text { Obese }\end{array}$ & $\begin{array}{l}\text { Extremely } \\
\text { Obese }\end{array}$ & $P$ Value* \\
\hline $\begin{array}{l}\text { All women } \\
\qquad(N=5,277)\end{array}$ & $\begin{array}{c}72 \\
(n=2,023)\end{array}$ & $\begin{array}{c}73 \\
(n=1,779)\end{array}$ & $\begin{array}{c}74 \\
(n=874)\end{array}$ & $\begin{array}{c}67 \\
(n=307)\end{array}$ & $\begin{array}{c}64 \\
(n=187)\end{array}$ & .11 \\
\hline $\begin{array}{l}\text { White women } \\
\qquad(N=3,880)\end{array}$ & $\begin{array}{c}74 \\
(n=1,632)\end{array}$ & $\begin{array}{c}74 \\
(n=1,259)\end{array}$ & $\begin{array}{c}74 \\
(n=607)\end{array}$ & $\begin{array}{c}66 \\
(n=192)\end{array}$ & $\begin{array}{c}66 \\
(n=105)\end{array}$ & .21 \\
\hline $\begin{array}{l}\text { Black women } \\
\quad(N=718)\end{array}$ & $\begin{array}{c}62 \\
(n=168)\end{array}$ & $\begin{array}{c}74 \\
(n=253)\end{array}$ & $\begin{array}{c}72 \\
(n=162)\end{array}$ & $\begin{array}{c}77 \\
(n=73)\end{array}$ & $\begin{array}{c}56 \\
(n=52)\end{array}$ & .04 \\
\hline
\end{tabular}

* $\mathrm{P}$ values refer to comparisons across different weight categories. $\mathrm{P}$ values for trend excluding underweight women were .08 for all women, .06 for white women, and .7 for black women.

significantly lower hospitalization rate compared to their normal weight counterpart (16\% vs 19\%). Both black and white women with obesity were significantly more likely to feel sad or hopeless in the last 30 days compared to normal weight women. However, being obese was significantly associated with feeling worthless only among white women; while $14 \%$ of white women with obesity reported feeling worthless, $8 \%$ of normal weight women had similar feelings.

\section{BMI and Mammography Use: Unadjusted Results}

Table 2 shows the unadjusted association between BMI and mammography use among all women in our sample and among white and black women separately. Among white women, rates were highest among nonobese women. Among black women, rates were highest among women who were moderately obese.

\section{BMI and Mammography Use Among Eligible Women Overall}

When we examined for a relationship between BMI and mammography use after adjusting serially for sociodemographic factors and access, illness burden, psychological functioning, and health habits, women with moderate to extreme obesity overall were least likely to report breast cancer screening, although the trend was not statistically significant $(P=.08)$. Results did not differ substantially among our adjusted models. Table 3 shows results from our primary analysis, which adjusted for sociodemographic factors, health care access, general health status, and illness burden (model 2).

\section{BMI and Mammography Use Among Eligible White Women}

Table 3 also shows the results for mammography use and BMI among white women from our primary model (model 2). The likelihood of undergoing mammography decreased with increasing BMI category among white women $(P$ value for trend $=.02)$. Compared to results from model 1, which was adjusted for sociodemographic factors, health care access and general health status, further adjustment for illness burden (model 2), psychological functioning (model 3), and health habits (model 4) did not change the relationship between mammography use and BMI substantially (Fig. 1).

\section{BMI and Mammography Use Among Eligible Black Women}

Among black women, mammography use increased with higher BMI except for women with extreme obesity, who had similar rates to normal weight black women (Table 3; Fig. 2); however, the trend was not statistically significant $(P=.30)$. Adjusting for different groups of factors did not change this relationship appreciably (Fig. 2).

\section{BMI and Mammography Use: Comparing Black and White Women}

In order to directly compare the relationship between mammography and BMI in black and white women, we excluded underweight women from our primary analysis (model 3) and added an interaction term for race and BMI.

Table 3. Relative Risk for Mammogram Use According to Weight Category for Women Age 50 to 75 Years After Adjusting for Demographic Factors, Health Care Access, Comorbid Conditions, and Mobility Status

\begin{tabular}{|c|c|c|c|c|c|}
\hline & $\begin{array}{l}\text { Normal } \\
\text { Weight }\end{array}$ & $\begin{array}{c}\text { Over- } \\
\text { weight }(95 \% \mathrm{Cl})\end{array}$ & $\begin{array}{c}\text { Mildly } \\
\text { Obese }(95 \% \mathrm{Cl})\end{array}$ & $\begin{array}{c}\text { Moderately } \\
\text { Obese }(95 \% \mathrm{Cl})\end{array}$ & $\begin{array}{c}\text { Extremely } \\
\text { Obese }(95 \% \mathrm{Cl})\end{array}$ \\
\hline $\begin{array}{l}\text { All women } \\
\qquad(N=5,004)\end{array}$ & 1.00 & $\begin{array}{c}1.01 \\
(0.95 \text { to } 1.06)\end{array}$ & $\begin{array}{c}0.99 \\
(0.91 \text { to } 1.05)\end{array}$ & $\begin{array}{c}0.89 \\
(0.77 \text { to } 1.01)\end{array}$ & $\begin{array}{c}0.88 \\
(0.71 \text { to } 1.01)\end{array}$ \\
\hline $\begin{array}{l}\text { White women } \\
\qquad(N=3,701)\end{array}$ & 1.00 & $\begin{array}{c}0.98 \\
(0.92 \text { to } 1.04)\end{array}$ & $\begin{array}{c}0.94 \\
(0.86 \text { to } 1.01)\end{array}$ & $\begin{array}{c}0.83 \\
(0.68 \text { to } 0.96)\end{array}$ & $\begin{array}{c}0.90 \\
(0.67 \text { to } 1.07)\end{array}$ \\
\hline $\begin{array}{l}\text { Black women } \\
\quad(N=670)\end{array}$ & 1.00 & $\begin{array}{c}1.19 \\
\text { (1.01 to } 1.32)\end{array}$ & $\begin{array}{c}1.22 \\
\text { (0.98 to } 1.39)\end{array}$ & $\begin{array}{c}1.37 \\
\text { (1.13 to } 1.50)\end{array}$ & $\begin{array}{c}0.95 \\
\text { (0.60 to } 1.25)\end{array}$ \\
\hline
\end{tabular}

CI, confidence interval. 


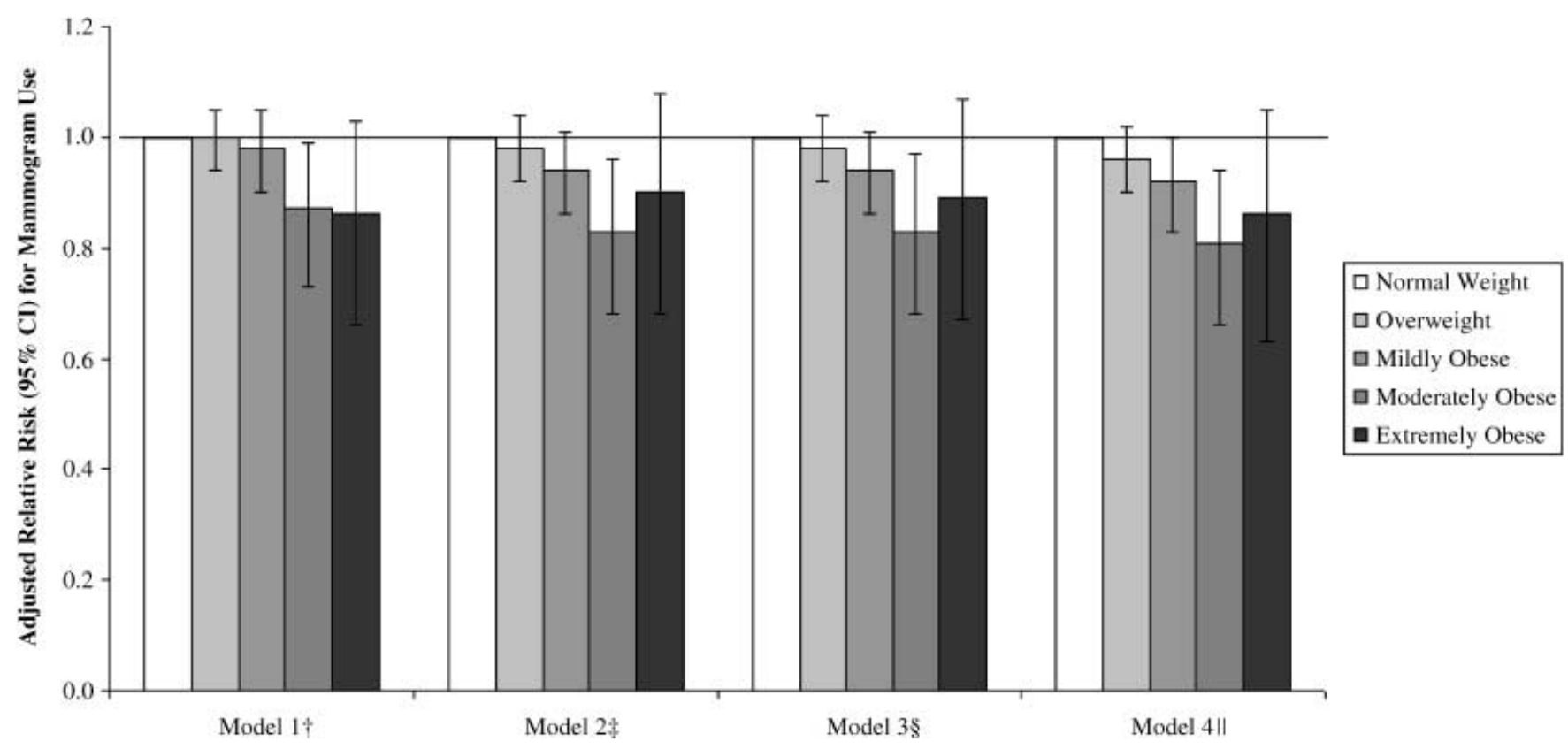

FIGURE 1. Influence of different factors on the relationship between BMl and mammography use among white women. ${ }^{*}$

* Normal weight women served as the reference group with a relative risk of 1.00.

† Model 1 was adjusted for sociodemographic factors, health care access, and general health status.

‡ Model 2 was adjusted for factors in model 1 and medical conditions, hospitalizations, and mobility status.

$\S$ Model 3 was adjusted for factors in model 2 and proxy for psychological functioning.

"Model 4 was adjusted for factors in model 3 and health habits (tobacco use, physical activity, and alcohol use).

We found the interaction to be statistically significant at $P=.001$. We also repeated our adjusted analyses combining both black and white women and using normal weight white women as the reference group (Fig. 3). Compared to the reference group, black women regardless of weight were generally as or more likely to report screening with mammograms, with moderately obese black women being $20 \%$ more likely to report screening after adjustment (Fig. 3). Prior to adjustment, normal weight black women were significantly less likely to report mammography use (RR, 0.82; $95 \%$ CI, 0.70 to 0.94 ) than normal weight white women; however, this was substantially attenuated by adjustment for sociodemographic factors, health care access, and general health status (RR, 0.92; 95\% CI, 0.79 to 1.04; model 2) and unchanged with further adjustment (models 3 and 4).

\section{Comment}

Our study suggests that among white women aged 50 to 75 years, higher BMI was modestly associated with lower breast cancer screening in a dose-response manner. White women with moderate obesity were least likely to undergo mammography. Among black women, however, higher BMI was associated with similar or greater use of mammograms. Differences in mammography use by race and BMI could not be explained by sociodemographic factors, health habits, or indicators for health care access, illness burden, or psychological functioning. We also noted that normal weight black women had significantly lower unadjusted rates of mammography use compared to their white counterparts; however, these differences were attenuated after accounting for differences in sociodemographic factors and health care access.

This study is a follow-up to an earlier study documenting lower mammography use among women with obesity even after adjustment for sociodemographic factors, health care access, and general health status. ${ }^{4}$ In that study, we used 1994 data to explore the influence of race on this association and found a suggestive dose-response relationship between lower mammography use and higher BMI among white women. Our results for black women, however, were inconsistent, possibly because of inadequate sample size. Furthermore, our earlier study lacked details on specific medical conditions, functional status, or psychological functioning. The current study uses a larger sample to address some of the limitations of our earlier work and allows us to examine the influence of race, illness burden, and other factors that potentially mediate or confound the relationship between weight and breast cancer screening.

We note several differences and similarities between our earlier and current findings. First, mammography use has improved substantially overall, from a rate of $65 \%$ in 1994 to $72 \%$ in 1998. Second, while the use of mammograms has increased for most groups we studied, the proportion among normal weight black women has actually decreased from approximately $74 \%$ to $62 \%$ between 1994 and 1998. Some of this difference was explained by differences in sociodemographic factors and health care access; 


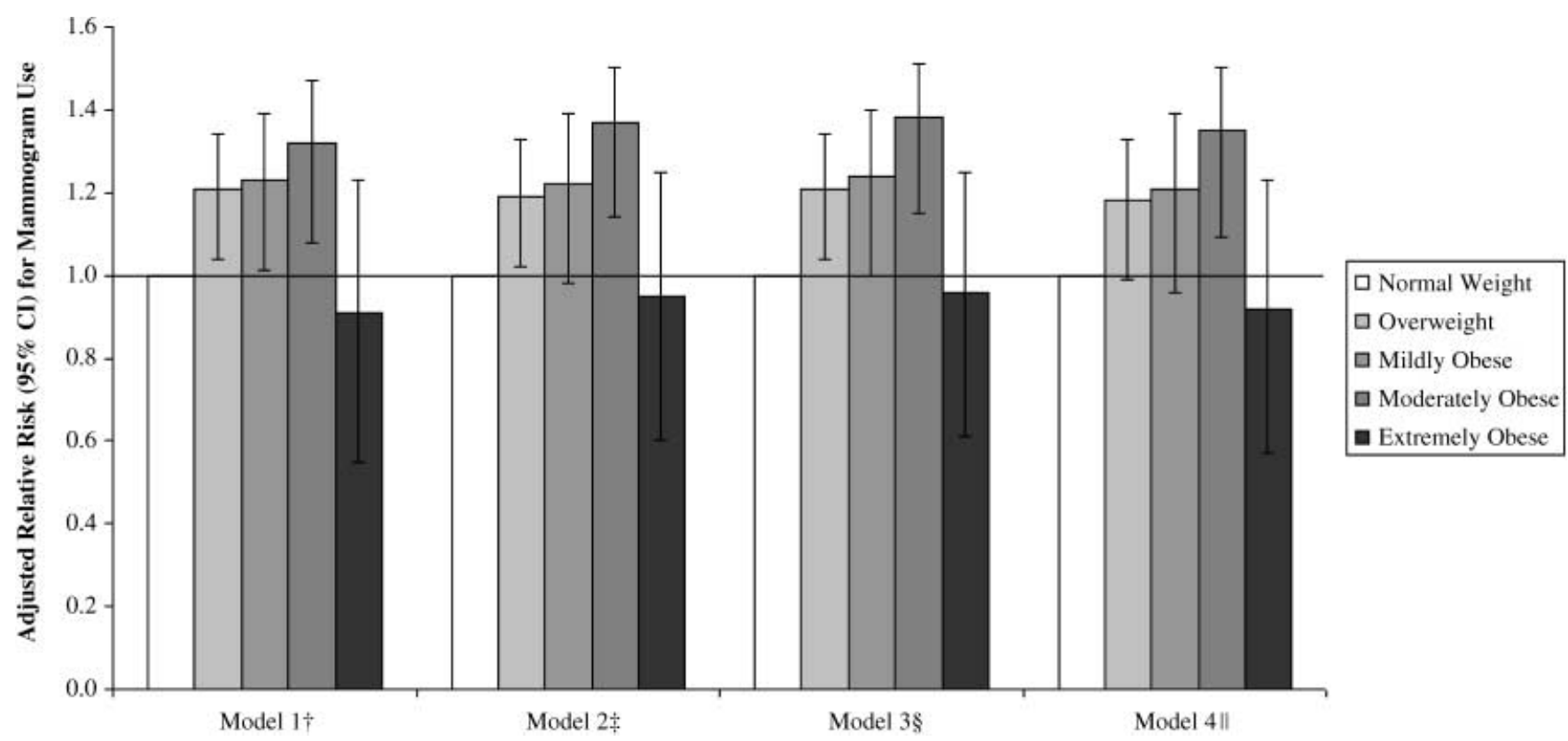

FIGURE 2. Influence of different factors on the relationship between BMl and mammography use among black women. *

* Normal weight black women served as the reference group with a relative risk of 1.00.

${ }^{\dagger}$ Model 1 was adjusted for sociodemographic factors, health care access, and general health status.

${ }^{\dagger}$ Model 2 was adjusted for factors in model 1 and medical conditions, hospitalizations, and mobility status.

$\S$ Model 3 was adjusted for factors in model 2 and proxy for psychological functioning.

" Model 4 was adjusted for factors in model 3 and health habits (tobacco use, physical activity, and alcohol use).

however, future studies should investigate specific factors responsible for this dramatic reduction. Third, while the relationship between breast cancer screening and BMI among black women was inconsistent in our earlier study, our current findings suggest that black women with higher BMI are as or more likely to undergo screening except for those with extreme obesity. Nevertheless, the disparities we previously noted between BMI and screening among white women appears to persist.

Although the lower proportion of screening among white women with higher BMI is relatively modest, our findings are concerning nonetheless because of the rising and high prevalence of obesity and because breast cancer is the most common cancer among women in the United States. ${ }^{19}$ Approximately 40,000 women die from breast cancer annually, accounting for $15 \%$ of cancer deaths among women. ${ }^{19}$ Moreover, white women with a BMI above $35 \mathrm{~kg} / \mathrm{m}^{2}$ represent $16 \%$ of all women aged 50 to 75 years (data available from authors) and are at higher risk for developing and dying from breast cancer. ${ }^{3}$ The mechanisms for this increased risk are unclear but may be related to physical inactivity, and hormonal and dietary factors. ${ }^{20-22}$ Fortunately, breast cancer deaths can be reduced substantially through early detection using mammograms. ${ }^{4}$ Moreover, while there are concerns about the quality of mammogram images in women with high adiposity, ${ }^{23}$ at least one study suggests that screening mammography may be equally beneficial in detecting early breast cancer for obese women and for normal weight women. ${ }^{24}$ Our study suggests, however, that this population of obese women, who are at high risk for breast cancer, is paradoxically less likely to undergo screening. Furthermore, screening did not appear to be driven by clinical factors that may influence life expectancy such as comorbidities and other proxies for illness burden in our study.

Unfortunately, we were unable to identify specific reasons for weight-related disparities in breast cancer screening. Despite the higher prevalence of known barriers to health care among women with obesity such as lower socioeconomic status and higher illness burden, adjusting for these factors did not influence our findings appreciably. Particularly striking was the minimal role that comorbid conditions, functional status, and other markers of illness burden seemed to play.

Our disparate findings between black and white women does suggest that patient-centered factors such as patient preferences and cultural beliefs may play a larger role in explaining differences in screening by BMI than either clinical factors or provider-driven factors. The selfperception associated with weight is one factor shown to differ between black and white women. ${ }^{10-12}$ Relative to their white counterparts, overweight black women are more likely to underestimate their weight category, to be satisfied with their bodies, and to feel attractive. ${ }^{10-12}$ In our study, obesity was associated with feeling worthless in the preceding 30 days for white but not black women. This qualitative difference in body image perception may interact with health behaviors, such that white women who are 


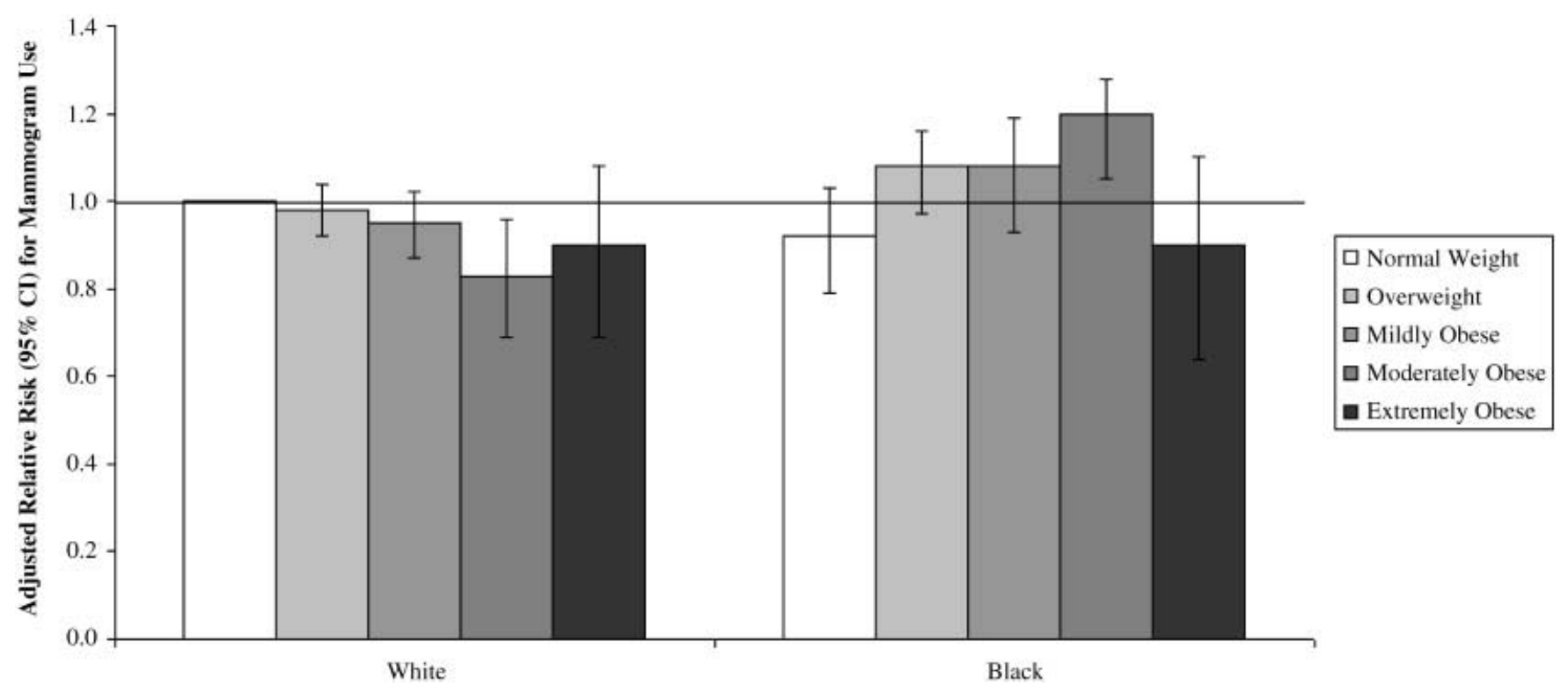

FIGURE 3. Mammogram use among black and white women by weight category compared to normal weight white women.* Normal weight white women served as the reference group. Analyses adjusted for sociodemographic factors, health care access, general health status, medical conditions, hospitalizations, and mobility status (model 2).

obese may be less willing to undergo mammograms. Adjusting for our proxy for self-esteem did not affect our findings related to BMI, screening, and race. However, our proxy likely did not completely capture the concept of low self-esteem or poor self-perception; therefore, future studies should use better measures to test the role of self-image in explaining disparities by BMI. Adjusting for health habits as a proxy for health-seeking behavior also did not explain differences by race and BMI. Thus, while our study does not point to specific mechanisms, it does suggest that disparities by weight and race are highly complex and warrant further study.

Although our findings make provider-driven factors such as bias against referring obese women for screening less likely, these findings do not exclude this possibility completely. One study found that when physicians were presented with similar patients who differed only by weight, physicians reported that they would prescribe more tests for the heavier patients, but spend less time with them. ${ }^{25}$ Another study found that obese women patients were more likely to refuse pelvic exams than thinner women and that physicians were less likely to pursue these exams if their patients refused. ${ }^{9}$ Hence, disparities in breast cancer screening may result from an interplay between patient preferences and provider biases. Obese women may have more reservations about undergoing mammograms than their normal weight or black women, and providers may not be spending enough time counseling about the importance of screening in a way that ameliorates patients' fears. Another possibility is that black women may select providers who have fewer racial biases, and these providers may also harbor fewer biases against patients who are overweight. The validity of these hypotheses should be explored in future research.

We used a rich database that generalizes nationally; however, our study has several limitations. First, all information was based on self-report and may be subject to reporting inaccuracies and recall bias. In particular, overweight women tend to overestimate their height and underestimate their weight to a larger extent than thinner women. ${ }^{26}$ Hence, disparities noted by BMI are potentially underestimated for obese white women and overestimated for normal weight black women. Second, despite the added detail in the 1998 NHIS, we likely did not control adequately for all confounders or explanatory factors. Specifically, our measures for self-esteem and depression were likely inadequate. Third, we were unable to control for many cancer risk factors, which may have influenced patients' preferences or providers' recommendations. However, we chose minimum screening recommendations so that these risk factors would be less likely to influence our outcomes. Finally, we were not able to control for provider characteristics, such as gender or race, or evaluate provider behavior, which are likely to influence screening. ${ }^{27}$

Nevertheless, our study demonstrates that white women with moderate obesity are less likely to undergo breast cancer screening with mammograms than normal weight white women. On the other hand, overweight and obese black women are as or more likely than both black and white normal weight women to report mammography use. Differences in screening by weight were not readily explained by differences in sociodemographic factors, health care access, indicators of illness burden, functional status, or 
health habits. More research is needed to determine the reasons for these disparities so that appropriate efforts can be made to improve screening in patients with obesity.

We thank the National Center for Health Statistics for providing the initial data. The analyses, interpretations, and conclusions in this manuscript, however, are those of the authors and do not reflect those of the National Center for Health Statistics.

The study was funded by grant R03 HS11683 from the Agency for Healthcare Research Quality (Dr. Wee). Dr. Wee is also the recipient of a career development award from the National Institute of Diabetes, Digestive, and Kidney Diseases (K23 DK02962). Dr. McCarthy is a recipient of a First Independent Research and Transition Award from the National Cancer Institute (R29 CA79052). Dr. Phillips is supported by a Mid-Career Investigator Award from the National Institutes of Health (K24 AT00589-01A1).

\section{REFERENCES}

1. Allison DB, Fontaine KR, Mansion JE, Stevens J, VanItallie TB. Annual deaths attributable to obesity in the United States. JAMA. 1999;282:1530-8.

2. McGinnis JM, Foege WH. Actual causes of death in the United States. JAMA. 1993;270:2207-12.

3. Calle EE, Rodriguez C, Walker-Thurmond K, Thun MJ. Overweight, obesity, and mortality from cancer in a prospectively studied cohort of U.S. adults. N Engl J Med. 2003;348:1625-38.

4. Kerlikowske K, Grody D, Rubin SM, Sandrock C, Ernster VL. Efficacy of screening mammography. A meta-analysis. JAMA. 1995;273:149-54.

5. Wee CC, McCarthy EP, Davis RB, Phillips RS. Screening for cervical and breast cancer. Is obesity an unrecognized barrier to preventive care? Ann Intern Med. 2000;132:697-704.

6. Cade J, O’Connell S. Management of weight problems and obesity knowledge, attitudes, and current practice of general practitioners. Br J Gen Pract. 1991;41:147-50.

7. Price JH, Desmond SM, Krol RA, Snyder FF, O'Connell JK. Family practice physicians' beliefs, attitudes and practices regarding obesity. Am J Prev Med. 1987;3:339-45.

8. Young LM. The effects of obesity on the clinical judgments of mental health professionals. J Health Soc Behav. 1985;26:233-46.

9. Adams CH, Smith NJ, Wilbur DC, Grady KE. The relationship of obesity to the frequency of pelvic examinations: do physicians and patient attitudes make a difference? Women Health. 1993;20:45-57.
10. Ofosu HB, Lafreniere KD, Senn CY. Body image perception among women of Africa descent: a normative context? Fem Psychol. 1998;8:303-23.

11. Flynn KJ, Fitzgibbon M. Body images and obesity risk among black females: a review of the literature. Ann Behav Med. 1998;20:13-24.

12. Caldwell MB, Brownell KD, Wifley DE. Relationship of weight, body dissatisfaction, and self-esteem in African American and white female dieters. Int J Eat Disord. 1997;22:127-30.

13. National Center for Health Statistics, 2000. Design and Estimation for the National Health Interview Survey, 1995-2004, Vital and Health Statistics, Series 2, No. 130.

14. U.S. Preventive Services Task Force. Guide to Clinical Preventive Services, 2nd edn. Baltimore, Md: Williams \& Wilkins; 1996.

15. Executive summary of the clinical guidelines on the identification, evaluation, and treatment of overweight and obesity in adults. Arch Intern Med. 1998;159:1855-67.

16. Iezzoni LI, McCarthy EP, Davis RB, Siebens H. Mobility impairments and use of screening and preventive services. Am J Public Health. 2000;90:955-61.

17. Wee CC, McCarthy EP, Davis RB, Phillips RS. Physician counseling about exercise. JAMA. 1999;282:1583-8.

18. Zhang J, Yu KF. What's the relative risk? A method of correcting the odds ratio in cohort studies of common outcomes. JAMA. 1998;280: 1690-1.

19. Greenlee RT, Murray T, Bolden S, Wingo PA. Cancer statistics, 2000. CA Cancer J Clin. 2000;50:7-33.

20. Henderson BE, Pike MC, Bernstein L, et al. Breast cancer. In: Schottenfeld D, Fraumeni JF Jr, eds. Cancer Epidemiology and Prevention, 2nd edn. New York, NY: Oxford University Press; 1996:1022-39.

21. Thune I, Brenn T, Lund E, Gaard M. Physical activity and the risk of breast cancer. N Engl J Med. 1997;336:1269-75.

22. Carroll KK. Obesity as a risk factor for certain types of cancer. Lipids. 1998;33:1055-9.

23. Guest AR, Helvie MA, Chan HP, Hadjiiski LM, Bailey JE, Roubidoux MA. Adverse effects of increased body weight on quantitative measures of mammographic image quality. Am J Roentgenol. 2000; 175:805-10.

24. Reeves MJ, Newcomb PA, Remington PL, Marcus PM, Mackenzie WR. Body mass and breast cancer. Relationship between method of detection and stage of disease. Cancer. 1996;77:301-7.

25. Hebl MR, Xu J. Weighing the care: physicians' reactions to the size of a patient. Int $\mathrm{J}$ Obes. 2001;25:1246-52.

26. Rowland ML. Self-reported weight and height. Am J Clin Nutr. 1990;52:1125-33.

27. Lurie N, Slater J, McGovern P, Ekstrum J, Quam L, Margolis K. Preventive care for women. Does the sex of the physician matter? N Engl J Med. 1993;329:478-82. 